\title{
The Local Political Context of Latino Partisanship
}

\section{Kenneth E. Fernandez}

College of Southern Nevada

\author{
Matthew C. Dempsey \\ Arizona State University
}

\begin{abstract}
The question of how partisanship is influenced by exogenous factors has been vigorously debated, yet this debate is less frequently noted in the literature on Latino partisanship. This study analyzes the 2006 Latino National Survey with geographic identifiers to explore how the political context of a county influences Latino partisan self-identification. There are a variety of reasons why the political environment might influence Latinos' partisan choice. First, a substantial proportion of the adult Latino population in the United States is foreignborn, potentially lessening the influence of parental partisan socialization. Second, increased migration to areas outside the Southwest has exposed Latinos to new and different social, political, and economic environments. Using subgroup analysis, interactive logit models, and regression discontinuity, we find that the local political context influences the party attachment of Latino immigrants in predictable ways. However, for Latinos born in the United States, our analysis does not provide evidence of a causal connection between partisan environment and an individual's partisan identification.
\end{abstract}

Keywords: Latino politics, party identification, partisan environment

The political party an individual chooses to support, if any, has been considered one of the most important determinants of individual-level political behavior (Campbell et al. 1960; Flanigan et al. 2014). Because of this, party identification is also one of the most widely studied topics in the field of political science (Medvic 2013). Yet, how citizens come to this partisan

Address correspondence and reprint requests to: Kenneth E. Fernandez, College of Southern Nevada, Las Vegas, NV. E-mail: kenneth.fernandez@csn.edu 
choice remains an enduring question. This is particularly true for immigrant populations, such as Latinos, since a traditional theory of how individuals develop partisan preferences stresses the importance of parental political socialization (Campbell et al. 1960; Valentino and Sears 1998). Given that some estimate over half of the Latino adult population was born outside the United States (Taylor and Fry 2007), parental influence regarding partisan identification may be less relevant for this group. As such, the traditional models of understanding partisanship in American politics may be inadequate in explaining Latinos' political behavior since Latino "socialization into American politics follows a different path" (Abrajano and Alvarez 2010, 65).

If Latinos' political incorporation follows a different path, what does that different path look like? It could depend on whether the path travels through Los Angeles, CA, or through Orlando, FL. This study examines how Latino partisan choices are influenced by the local political context of an area, specifically the partisan makeup of a county. Due to the explosive growth of the Latino population outside of their traditional areas of settlement within the United States (Lichter and Johnson 2009), coupled with the growing geographic political polarization of the United States (Tam Cho, Gimpel and Hui 2013), we expect these local environments to influence Latino party identification, especially Latinos born outside the United States.

This paper proceeds as follows. The first section reviews the literature and debate regarding the stability or malleability of partisan attachments. We then discuss how the political environment could influence partisanship, especially among newer arrivals to the country. The data and measures section describes the survey data used in the study and how the primary variables of interest are measured. The methodology section discusses how the causal relationship between partisan environment and individual party self-identification is tested using three techniques: subgroup analysis, interaction terms, and regression discontinuity (RD). This is followed by a presentation of the findings and a discussion of their implications. The results from this study highlight the importance of incorporating characteristics of the local environment in which an individual lives when studying political attitudes and behavior.

\section{THE NATURE OF PARTY IDENTIFICATION: STABLE OR MALLEABLE}

The amount of research on party identification is extensive, yet there is still a lack of consensus on the nature and meaning of partisanship. Early 
conceptions often viewed partisanship as an affective attachment to a political party that develops early in life and remains, for the most part, stable. This view of the acquisition of partisanship considers the family, and parents especially, to be a primary source of political socialization (Campbell et al. 1960). While some scholars have suggested this relationship is somewhat overstated (Abramowitz and Saunders 1998), others claim there is still a considerable level of partisan congruency between parent and child (Zuckerman, Dasovic, and Fitzgerald 2007). This school of thought is sometimes referred to as the "Michigan school" or the "traditionalist" approach (Bartels et al. 2011; Hajnal and Lee 2011), and is connected with the classic work, The American Voter (1960). This view of partisanship generally maintains that partisan attachment is largely immune to politics.

Alternatively, the "Downsian" approach views partisan identification as much more malleable and something that is continuously modified to account for party positions on issues and the personal evaluation of political leaders and political campaigns (Downs 1957; Fiorina 1981). Instead of partisanship being an "unmoved mover", where it influences behavior but is not affected by politics, Fiorina's $(1981,84)$ retrospective model saw partisanship as a "running tally of retrospective evaluations of party promises and performance." This approach is sometimes referred to as the "revisionist" approach (Bartels et al. 2011).

Yet these two dominant theories of partisanship generally have said little about how the local environment may influence a person's partisan attachment. The Michigan model considers voters to have a long-standing, psychological attachment to a party similar to religious convictions and therefore contextual factors were unlikely to have any direct influence on party identification (Campbell et al. 1960). The retrospective model of partisanship conceptualizes partisanship as far less stable and more susceptible to change than the traditional approach. An important element of this type of Downsian approach is that respondents learn and respond to new information, but the source of this information is usually modeled as coming from changes in the larger, national context (e.g., Bartels and Jackman 2014), not the local context.

\section{CONTEXTUAL EFFECTS AND LATINO PARTISANSHIP}

The debate over the stability of partisanship is highly relevant to the study of how the environment effects partisan affiliation. If partisanship is stable 
over a person's life, as predicted by the Michigan model, then the environment is likely to be irrelevant. Conversely, if partisan attachments follow a Downsian model where individuals consume and evaluate new information regarding the political parties, then the environment could be an important source of information. Hajnal and Lee (2011, 20) note "informational environments" are one of three key factors in determining whether an individual will affiliate with a party and which party that might be.

Recent studies on partisanship seem to borrow from both the Michigan and the Downsian schools of thought (Hajnal and Lee 2011; Sniderman and Stiglitz 2012). Grofman, Wayman, and Barreto $(2009,71)$ suggest that "pitting" the traditionalist and revisionist approaches against each other is "counterproductive". We agree and believe that both may provide some illumination on how and when local partisan context influences Latino partisan affiliations.

The traditionalist approach highlights the importance of parental socialization, yet even revisionist approaches like that of Achen (2002) suggest children may often use their parents' party identification as a form of Bayesian 'prior beliefs' when evaluating political parties. Given that immigrants, the children of immigrants, and later generations of Latinos may have very different political experiences, we suspect that the level of parental influence and the level of stability in partisan attachments will vary depending on which generation one is examining. The environment could be especially relevant to the political development of more recent generations of Latinos who do not always follow a traditional path in the acquisition of partisanship (Abrajano and Alvarez 2010). This is because an immigrant would have parents who have little or no association with the U.S. party system. This diminished influence of parental socialization on partisan choice could even apply to the children of immigrants, since their foreign-born parents might not have strong attachments to any one political party (Hajnal and Lee 2011).

Our argument that the political environment affects partisanship stems from the belief that "where and with whom individuals live combine with their personal characteristics to influence" their political behavior (Campbell, Wong, and Citrin 2006, 129). This interaction has been explored in numerous studies; however, these studies have typically examined how the environment influences attitudes on various issues, but have neglected how such environments influence partisan attachments. The few studies that do explore how local environments influence partisanship have generally not examined Latino partisanship. 
We argue there are reasons why early generations of Latinos are more likely to be influenced by local environments than other groups. DeSipio (2011) suggests modern American immigrants are exposed to government and politics primarily at the state and local level. This suggests the extent to which immigrants learn about politics depends largely on where they live. An important point made in this study is that where Latino and Latino immigrants live have begun to change. Latinos are beginning to move from the traditional urban and Southwestern regions of the United States to other areas of the country. These new living conditions differ substantially in their racial and political makeup, and we posit that these living conditions could have an important impact on the acquisition of partisan identification of Latinos.

Furthermore, the effects of the political environment on Latino partisanship may be more observable given the partisan attachment of this group appears to be far from cemented. Compared with African Americans, where $90 \%$ of those surveyed have some attachment to the Democratic Party (Thurber 2013), it is more difficult to place Latinos within one particular party (de la Garza et al. 1992). The 2006 LNS found approximately $36 \%$ of Latino respondents considered themselves Democrats compared with 11\% Republican, $17 \%$ independent, $16 \%$ who said they do not care, and $20 \%$ who did not know or identified with a different party (see Table 1). The clear advantage the Democratic Party has over the Republican Party regarding Latino supporters has not discouraged Republican strategists who see Latinos as a potential pool of new supporters because of their traditional family values (Baik, Lavariega-Monforti, and McGlynn 2009; Dutwin et al. 2005). How successful the Republican Party has been in recruiting Latino support for Republican candidates is debatable. Nicholson and Segura (2005) are doubtful of the Republicans' ability to attract Latinos, whereas others have observed some Republican gains (McDaniel and Ellison 2008) or see "the dynamics of social trends among Hispanics...to favor the Republican Party" (Kosmin and Keysar 1995, 336). Alternatively, scholars point to the growing choice of not attaching to one of the two dominant parties, especially among new immigrant groups and thus for these groups "this partisan competition is far from predetermined" (Hajnal and Lee 2011, 4).

Therborn (2008) notes that all democracies exhibit a spatial pattern of voting, with people from different groups (class, race, religion) voting differently depending on where they live, but the reason for these spatial differences are not well known. If the environment influences 
Table 1. Latino Partisanship by State-Source: 2006 Latino National Survey ${ }^{\mathrm{a}}$

\begin{tabular}{|c|c|c|c|c|c|c|}
\hline State & Democrat & Republican & Independent & $\begin{array}{l}\text { Do not } \\
\text { care }\end{array}$ & $\begin{array}{l}\text { Do not } \\
\text { know or } \\
\text { other party }\end{array}$ & $N$ \\
\hline New York & $51.9 \%$ & $6.9 \%$ & $12.6 \%$ & $12.8 \%$ & $15.9 \%$ & 800 \\
\hline New Mexico & 46.8 & 13.0 & 12.3 & 11.8 & 16.3 & 400 \\
\hline Arizona & 43.0 & 9.0 & 16.0 & 13.0 & 19.0 & 400 \\
\hline Illinois & 41.3 & 8.0 & 15.5 & 15.8 & 19.3 & 600 \\
\hline New Jersey & 40.2 & 12.7 & 16.4 & 12.9 & 17.9 & 403 \\
\hline Texas & 39.1 & 9.6 & 15.8 & 14.9 & 20.6 & 811 \\
\hline California & 37.8 & 10.1 & 16.3 & 16.0 & 19.8 & 1,204 \\
\hline Maryland & 35.5 & 10.8 & 21.1 & 18.7 & 13.9 & 166 \\
\hline Colorado & 33.9 & 11.1 & 20.0 & 13.4 & 21.5 & 404 \\
\hline Virginia & 33.5 & 9.7 & 18.2 & 16.5 & 22.2 & 176 \\
\hline Nevada & 32.3 & 10.9 & 19.1 & 20.1 & 17.6 & 403 \\
\hline Iowa & 31.8 & 9.0 & 17.8 & 20.0 & 21.5 & 400 \\
\hline Washington & 30.3 & 9.9 & 19.4 & 20.6 & 19.9 & 403 \\
\hline Florida & 26.4 & 24.5 & 16.0 & 15.5 & 17.6 & 800 \\
\hline Arkansas & 24.2 & 10.7 & 21.2 & 20.0 & 23.9 & 401 \\
\hline Georgia & 20.5 & 11.8 & 17.5 & 18.0 & 32.3 & 400 \\
\hline $\begin{array}{l}\text { North } \\
\text { Carolina }\end{array}$ & 20.0 & 10.0 & 17.0 & 25.2 & 27.9 & 401 \\
\hline $\begin{array}{l}\text { Total LNS } \\
\text { Sample }\end{array}$ & 35.7 & 11.2 & 16.6 & 16.3 & 20.1 & 8,634 \\
\hline
\end{tabular}

${ }^{\mathrm{a}}$ Unweighted proportions.

partisan choices, it is likely these factors do not work uniformly for all groups, since different groups often live in very different contexts (Marschall and Stolle 2004; Ramakrishnan 2005). Economic downturns, scandals, rally events, and elections are likely to influence observers and participants (Smidt 2014), but these events may impact different groups and generations in different ways and/or degrees. Furthermore, states, regions, and localities could experience these events differently (Kosmin and Keysar 1995), and thus Latinos might experience economic and political events very differently depending on where they live. This regional difference in political context can be seen in CA where a variety of antiimmigrant ballot initiatives and campaigns created a politically charged environment that had a measurable effect on Latino partisanship (Bowler, Nicholson and Segura 2006; Dyck, Johnson and Wasson 2012).

Prior scholarship has not highlighted the role of local contexts on Latino partisanship since it is often argued that "an important feature of the Latino experience is the increasingly segregated concentration of 
large numbers of Latinos in a handful of states in large, urban areas polarized by racial tensions" (Contreras 2004, 228). Similarly, Geron (2005, 5) "makes the case that the Latino community in the 21 st century has developed common political experiences, whether they live in Lawrence, Massachusetts; Orlando, Florida; Brownsville, Texas; Cicero, Illinois; Pueblo, Colorado; or Oakland, California, and these similar experiences cross state lines and regional particularities." In this study we highlight the importance of different political environments in understanding Latino partisanship. MacDonald and Franko (2008) note the United States has a highly mobile population with approximately $2.5 \%$ of residents moving state to state annually. This is especially true for Latinos who are moving away from their traditional urban centers and moving away from the Southwest region. In recent years the Midwest and the South have had some of the largest Latino population gains in the nation (Liaw and Frey 2007).

This migration away from urban centers and to the Midwest and South should have an important influence on the political socialization of Latinos. Although Campbell et al. (1960, 150) presented arguments supporting the stability of partisanship, they also noted that a change in environment may expose an individual to neighbors with different partisan views and such exposures can "foster change in identification." In addition, there is evidence that the United States is becoming more geographically polarized and different parts of the country are drifting apart from one another (Tam Cho, Gimpel and Hui 2013). This is important because if states and counties have drifted apart politically, then the migration of Latinos to areas outside urban centers and the Southwest region may bring Latinos into contact with very different political climates. Party registration data show substantial variation in partisan environment across different counties, from as low as $7 \%$ Democratic to as high as 95\% (McGhee and Krimm 2009). The combination of increased rates of migration of Latinos to different parts of the country and the geographic polarization of the United States should increase the likelihood of contextual conditions influencing Latino party identification.

\section{EXAMINING THE CAUSAL RELATIONSHIP BETWEEN CONTEXT AND PARTISANSHIP}

Table 1 displays the distribution of responses to the survey question, "Generally speaking, do you usually consider yourself a Democrat, a 
Republican, an Independent, some other party, or what?" Across the 17 states in the 2006 Latino National Survey (LNS) NY has the largest proportion of Latino respondents that self-identify as Democrats (52\%) with NC with the least (20\%). Kosmin and Keysar (1995) found that the best predictor of Hispanic partisan preference was state of residency. Does this mean that Latinos in NY have acclimated to the political culture of that state? Such an interpretation based on aggregated results would be based on an ecological fallacy. An individual-level analysis that incorporates contextual conditions is required to examine such a relationship, but any association between an individual's partisanship and partisan context could simply be due to sampling from homogeneous clusters, not evidence of a causal relationship. Or the casual direction could be reversed, in that a respondent who leans toward a particular party might choose to live in a county or state that has people with similar political attitudes (Tam Cho, Gimpel and Hui 2013).

Uncovering the causal relationship between individual partisanship and county political context is difficult without panel data to track respondents over time. We attempt to solve this problem using several techniques. First, we split the sample into subgroups to examine how the relationship between environment and an individual's partisanship may vary depending on whether they or their parents were born in the United States. The second approach involves the creation of interaction terms to examine how the relationship between partisan environment and partisan identification is moderated by how long a respondent has lived in that environment. Third, we conduct a RD analysis to provide further evidence that partisan environment influences self-reported party identification.

\section{DATA AND MEASURES}

This study uses data from the 2006 LNS, which was conducted in both Spanish and English between November 172005 and August 42006 (ICPSR 20862). The dataset contains 8,634 respondents from 17 states and 629 different counties and the District of Columbia. Traditional national samples of Latinos generally have up to half of their respondents sampled from California and Texas, preventing any large-scale contextual analysis. The large sample size of the LNS spread across 17 states and 629 counties allows for the dataset to be merged with other data containing information on county characteristics. This combined dataset provides a large sample size that covers a large number of counties, allowing a 
unique opportunity to explore how Latino partisanship varies across political contexts. This section describes how a respondent's partisan attachment is measured, how the partisan environment of a respondent is measured, and briefly discusses the control variables used in the analyses.

\section{Dependent Variable: Self-Reported Partisan Identification}

We use a 7-point scale to measure individual partisanship which includes the following categories: 1-strong Republican; 2-Republican; 3-lean Republican; 4-Indpendent or Don't Care; 5-lean Democrat; 6Democrat; 7-strong Democrat. This scale is developed using three survey questions. The first item asks respondents "Generally speaking, do you usually consider yourself a Democrat, a Republican, an Independent, some other party, or what?" A follow-up question asks those respondents who identified as a Democrat or Republican, "would you consider yourself a strong [Democrat/Republican], or not a very strong [Democrat/ Republican]?" Respondents who identify as independents or with another party were asked "do you think of yourself as closer to the Republican or Democratic Party?"

Similar 7-point scales have been widely used and seen as a reasonably good measure of partisanship attachment (Niemi and Weisberg 2001). Conversely, Miller (1991) argued a 3-point scale that simply differentiates between Republicans, Democrats, and Independents as a preferable measure of party identification. Using a similar 3-point measure produced no substantive differences in results or interpretations [results not shown]. Nevertheless, the 7-point scale was found to have a stronger association with partisan environment.

\section{Contextual Variable: Partisan Environment}

Our main explanatory variable of interest measures the political context of the county where the respondent resides. We use the Federal Information Processing Standard code to link a county to each respondent in the LNS. Context can be measured at many different levels but county-level measures have some advantages. A person's political context is not confined to their neighborhood or census block and a county-level measure is better able to capture the environment a person is exposed to (Branton and Jones 2005). Furthermore, Brown (1988, 19) suggests "crossing a county 
boundary is...sufficient to bring about a qualitative change in local political environments."

We measure political context using the share of the vote that the Democratic presidential candidate received in a county, averaged over two elections (2000 and 2004). ${ }^{1}$ McGhee and Krimm (2009) suggest vote share is not an accurate measure of partisanship because one cannot assume that a person who voted for a candidate is a member of that party since the voter has "no viable alternative to the major-party candidates (345)." Instead, the authors use party registration statistics at the county level to measure party support. They argue it is a more valid measure of the partisan make up of a county because voters can register as Independents or with a third party and still vote for a candidate from the two major parties in the general election.

One limitation of using party registration data is that in 2004 only 26 states asked for party affiliation on their registration forms (McGhee and Krimm 2009) and only 11 of these states coincide with the 17 states in the LNS. Using registration data requires excluding six states (AR, GA, IL, TX, VA, WA), which excludes 2853 respondents, a third of the cases in the LNS, and 278 counties (approximately 44\%). Although vote share in a presidential election may not be as direct a measure of the partisan makeup of a county, the availability of the data for all counties makes it a useful indicator. We replicated our analysis using data from McGhee and Krimm (2009) and found no substantive differences in results [results not shown].

\section{Subgroups: Generation 1.0-3.0}

We hypothesize that partisan environment could be more influential on partisan choice for respondents not born in the United States. We conduct a subgroup analysis by splitting the sample into two groups: those born in the continental United States and those born outside the continental United States. ${ }^{2}$ However, whether a person is born in the United States does not completely capture the diversity of experiences within the immigrant community. First generation Latinos who arrive in the United States later in life (generation 1.0) may have very different experiences than Latinos who arrive in the United States at an earlier age (often referred to as generation 1.5). Latinos who have spent much of their early childhood in the United States could have more in common with U.S. born Latinos whose parents are both born outside 
the United States (generation 2.0) than they do with their parent's generation (Portes and Rumbaut 2001). Similarly, Ramakrishnan (2004) finds Latinos with only one parent born in the United States (sometimes referred to as generation 2.5) may have different experiences than Latinos with parents who were both born in the United States (generation 3.0). To account for these differences we examine the relationship between partisan context and individual partisanship by estimating our models separately for each subgroup (Generation 1.0, 1.5, 2.0, 2.5, and 3.0). We expect the impact of partisan environment on partisan attachment should be stronger for earlier generations of Latinos.

\section{Moderating Variable-Length at Current Residence}

If the partisan environment influences an individual's partisan choices we would expect that this influence would be conditioned by various factors or moderating variables. How long a respondent has lived in a partisan environment would likely affect the strength of the relationship between environment and partisanship. A respondent who has lived in the same area for a longer time will have experienced a higher number of election cycles in that community providing opportunities to be exposed to the partisan environment (McBurnett 1991). For example, the longer a person has lived in an area the longer they will have been exposed to the local media.

Studies have shown that profit-maximizing newspapers respond to consumer preferences and "slant" their coverage to match the political preferences of the average reader (Gentzkow and Shapiro 2010). Moreover, a number of studies have found that the content of media (e.g., campaign advertising, editorial slant) can influence political perceptions and voting behavior (Druckman and Parkin 2005; Winneg, Hardy, and Jamieson 2013). Therefore, local media can help transmit the partisan environment to individuals and this transmission becomes more likely the longer individuals live in the community.

To test this hypothesis an interaction term is created by multiplying the partisan context measure (the focal independent variable) and the LNS item asking respondents how many years they have lived at their current address (the moderator variable). ${ }^{3}$ This interaction term is then used in a regression to explore the mechanism by which a partisan context could be transmitted to an individual and influence party identification. The use of this moderator variable tests whether the size or sign of the 
association between context and partisanship depends on how long a respondent has lived at their current residence. This technique helps specify the casual mechanisms by specifying under what conditions an explanatory variable operates and transmits its effect on the dependent variable (Cox and Wermuth 2004; Hayes 2013).

\section{Individual-Level Control Variables}

Because our moderator variable is the length an individual has lived at their current residence it is crucial to control for age. We include two measures of age: Younger and Older. The Younger variable represents respondents who are age 18-25 and Older represent respondents who are 55 or older. Younger respondents are the least likely to be attached to the Democratic Party and older respondents are the most likely to selfidentify as Democrats (Cain, Kiewiet, and Uhlaner 1991; Hajnal and Lee 2011). The number of years that a respondent has lived at their residence is likely to be correlated with age and age will likely to be associated with levels of assimilation and political incorporation. By including the age variables we make sure our length at current residence measure is not simply a surrogate measure for the age of a respondent.

We also include a variety of control variables identified by previous studies as associated with Latino partisanship. These include religion (McDaniel and Ellison 2008), education (Contreras 2004), national identity (Alvarez and Bedolla 2003), voter registration status (Dutwin et al. 2005), union membership (Cain, Kiewiet, and Uhlaner 1991), language preference (Johnson, Stein, and Wrinkle 2003), military service (Barreto and Leal 2007), family economic condition (Dutwin et al. 2005), and political ideology (Alvarez and Bedolla 2003). ${ }^{4}$ Even when these individual-level characteristics are controlled for we predict that the political context of a county will still have a statistically significant relationship with a respondent's partisanship.

\section{Contextual-Level Control Variables}

In addition to partisan context we also include four social and economic contextual variables as controls: the median income of a county, the size of the county Hispanic population in 2005 (percent logged), whether or not a county has a population density of 1000 or more residents per square mile in 2005, and whether or not a respondent lives in a Southwestern 
state (AZ, CA, NV, NM, TX). It is important to include county-level control variables since the association between individual partisanship and county party registration might be a reflection of other conditions in an area (Durand and Eckart 1976). Counties with large Hispanic populations, poorer communities, urban areas, and areas in the Southwest are expected to be more heavily Democratic (Leigh 2005). We expect a county's partisan context will influence Latino partisanship at the individual level, even when controlling for these other contextual factors.

\section{ANALYSIS AND RESULTS}

We hypothesize that the strength of the relationship between political context and a Latino's partisan attachment will be stronger for earlier generations. This is because it is expected that early political socialization will be less of a determinant in partisan choice for these individuals. To test this hypothesis we conducted separate analyses for the following groups: (a) all respondents in the LNS, (b) respondents who came to the United States after the age of 12 (generation 1.0), (c) respondents who immigrated to the United States before the age of 13 (generation 1.5), (d) respondents who are born in the United States, but whose parents are both born outside the United States (generation 2.0), (e) respondents who have one parent born in the United States (generation 2.5) and (f) respondents with both parents born in the United States (generation 3.0).

Table 2 presents the results for the six ordered logistic regressions. The dependent variable is the 7-point partisan scale and the primary independent variable of interest is the average share of the vote that the Democratic Presidential candidate received for the 2000 and 2004 general election. Partisan context (county share of Democratic vote) is positively associated with the partisan attachment for Latinos belonging to generations 1.0, 1.5, and 2.0. This association is not statistically significant for respondents born in the United States with at least one parent born in the United States.

We might explain this by referencing the "traditionalist" approach to partisanship, which stresses parental socialization as a prominent factor in a person's party identification. Furthermore, this provides some evidence that there is a causal relationship and the direction of that relationship runs from partisan environment to partisan choice. If the relationship was simply due to sampling from homogeneous clusters we would expect to see the county contextual measure to be associated with all Latinos, regardless of generation. It is possible that Latinos who are members of 
Table 2. Ordered Logit: Partisan Context and Individual Party Identification

\begin{tabular}{lllllll}
\hline & & Generation & Generation & Generation & Generation & Generation \\
& All Latinos & 1.0 & 1.5 & 2.0 & 2.5 & 3.0 \\
\hline \% Vote for Democratic Presidential & $\begin{array}{l}1.314^{* * * *} \\
\text { Candidate (2000-04) }\end{array}$ & $.990^{* * *}(.314)$ & $1.635^{*}(.788)$ & $2.651^{* * *}(.818)$ & $1.083(.810)$ & $1.310+(.701)$ \\
\# Obs & 7,141 & 4,076 & 851 & 827 & 494 & 873 \\
\# Counties & 603 & 470 & 239 & 232 & 196 & 257 \\
Pseudo $R^{2}$ & .0327 & .0320 & .0391 & .0332 & .0313 & .0585 \\
\hline
\end{tabular}

$+p<.10, * p<.05, * * p<.01, * * * p<.001$.

Control variables for all models include: Median income in county; percent of population that is Hispanic in a county (logged); whether a county is located in Southwestern state; urban county; length at current residence; younger (age 18-25); older (age 55 or older); college educated; Cuban; frequency of newspaper reading; homeownership; unemployed; government assistance; Catholic; registered to vote; liberal; union member; military service. 
different generation choose to live in different areas. Latinos born in the United States are more likely to live in urban areas, which are more heavily Democratic. Even though the models control for urban areas the results in Table 1 do not conclusively show a causal connection between environment and party identification and further analysis is needed.

\section{The Conditional Relationship between Context and Partisanship}

A number of scholars suggest that one way to strengthen causal claims when using non-experimental data is to more clearly specify the complexity of the relationship being tested. Instead of simply testing a single hypothesis, we can make hybrid hypotheses of how the magnitude of a relationship between two variables will change among different subgroups or how the relationship could be influenced by a moderating variable (Cox and Wermuth 2004; Hayes 2013). We further explore the relationship between partisan environment and individual partisan attachment by using interaction terms to examine how such a relationship is conditioned by how long a respondent has lived in that environment. Several scholars have used interaction terms to uncover the causal relationship between a person's attitude or behavior and their environment. The use of an interaction term can help identify the mechanism by which the environment influences the individual. Durand and Eckart (1976) attempted to address a similar causality problem by creating an interaction term between a partisan contextual variable ( percent Democrat) and the likelihood of intra-unit exchange (a survey item asking how often neighbors are visited). Similarly, Johnson, Shively, and Stein (2002) create an interaction term between a persons' perception of the partisan makeup of their neighborhood and the latency of that perception. This latency is measured by how quickly the respondent could describe the partisan makeup of their neighborhood.

As noted above we created an interaction term by multiplying our partisan context variable ( proportion of the vote in a county going to the Democratic presidential candidate in 2000 and 2004) with a survey item which asks respondents how long they have lived at their current residence. Such a product term helps determine if the effect of one variable on the dependent variable is conditioned on the value of a third variable. With this interaction term we are predicting that the effect of the partisan context measure increases as the amount of time a respondent lives at their 
current residence increases. If the partisan environment influences party identification we would expect the strength of that influence would be contingent on how long a resident is exposed to that environment. An interaction term that is positive and statistically significant would provide some evidence partisan context influences partisan choice and is not just a sampling artifact. ${ }^{5}$

Table 3 shows the results from four ordered logit models measuring partisanship as a 7-point scale. ${ }^{6}$ The first model (Model 1) uses all respondents in the LNS dataset. Model 2 re-estimates Model 1 but includes only respondents born in the continental United States. Model 3 applies Model 1 only to Latino respondents born outside the continental United States and Model 4 includes all respondents and a three-way interaction term that includes a dichotomous measure of whether a respondent is an immigrant, the measure of how long they have lived at their current residence, and the measure for a county's partisan context.

The two-way interaction term is positive and statistically significant only for the model applied to respondents not born in the United States (Model 3). Interpreting models with interaction terms can be difficult. Reviews of past studies using interaction terms frequently find authors misinterpreting results (Brambor, Clark, and Golder 2006). When interpreting interaction terms, one should not simply examine the size and sign of the coefficients or even the level of statistical significance (Jaccard 2001). One should also graphically show the predicted probabilities and the marginal effects of the focal variable, conditioned on the moderator variable (Brambor, Clark, and Golder 2006). Figure 1 presents the predicted probabilities of being a strong Democrat and the marginal effects of partisan context, given a changing value for the amount of time a respondent has lived at their current residence for Model 3 (Latinos born outside the United States). The interaction term was statistically significant in Model 3 and Figure 1 illustrates how the influence of partisan context on partisanship appears to be conditioned by the moderator variable (length at residence). Therefore, there is evidence that the association between county partisan context and individual party attachment changes depending on how long a respondent has lived in that county. At least this appears to be the case for respondents not born in the continental United States.

Comparing the effects of a moderating variable across subgroups (respondents born in the United States and those who are not) is a common way of further exploring and probing conditional relationships. However, this approach does not allow identification of potential 
Table 3. Ordered Logit-Interactive Models

\begin{tabular}{|c|c|c|c|c|}
\hline & $\begin{array}{l}\text { Model 1: all } \\
\text { respondents }\end{array}$ & $\begin{array}{l}\text { Model 2: U.S. } \\
\text { born respondents }\end{array}$ & $\begin{array}{l}\text { Model 3: foreign } \\
\text { born respondents }\end{array}$ & $\begin{array}{l}\text { Model 4: all respondents } \\
\text { (with 3-way interaction) }\end{array}$ \\
\hline \multicolumn{5}{|l|}{ County - level variables } \\
\hline \% Vote democrat (centered) & 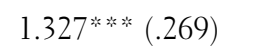 & 1.767 **** $(.456)$ & $1.244 * * *(.336)$ & 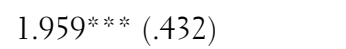 \\
\hline Median income $(/ 1,000)$ & $-.000(.003)$ & $-.007(.005)$ & $.002(.003)$ & $.000(.003)$ \\
\hline \%Hispanic Pop. (logged) & $.016(.039$ & $.010(.067)$ & $.001(.051)$ & $.016(.039)$ \\
\hline Southwest Region & $.120+(.066)$ & $.194+(.115)$ & $.092(.083)$ & $.116+(.065)$ \\
\hline Urban county & $.088(.076)$ & $.056(.133)$ & $.142(.092)$ & $.092(.076)$ \\
\hline \multicolumn{5}{|l|}{ Interaction terms } \\
\hline$\%$ Vote $\times$ Length at Residence & $.013(.023)$ & $-.053+(.029)$ & $.071^{*}(.033)$ & $-.067 *(.030)$ \\
\hline$\%$ Vote $\times$ Length at Residence $\times$ Immigrant & - & - & - & $.142^{* * * *}(.041)$ \\
\hline$\%$ Vote $\times$ Immigrant & - & - & - & $-.707+(.425)$ \\
\hline Length at Residence $\times$ Immigrant & - & - & - & $-.027^{*}(.012)$ \\
\hline \multicolumn{5}{|l|}{ Individual-level variables } \\
\hline Length at residence (centered) & $.012 *(.006)$ & $.020 *(.006)$ & $-.001(.011)$ & $.025^{* * * *}(.006)$ \\
\hline Immigrant & & & & $-.081(.114)$ \\
\hline Younger (18-25) & -.223 米的 $(.064)$ & $-.142(.121)$ & $-.335^{* * 2 *}(.080)$ & $-.244^{\text {的的 }}(.063)$ \\
\hline Older $(50+)$ & $.350^{* \ldots * \cdots *}(.094)$ & .572 皮和 $(.157)$ & $.252+(.132)$ & 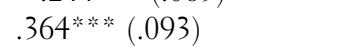 \\
\hline Education & $.039 *(.014)$ & $.021(.038)$ & $.050 *(.018)$ & $.038 *(.014)$ \\
\hline Cuban & 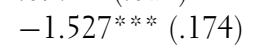 & $-.674 *(.336)$ & $-1.914^{\text {和的 }}(.171)$ & $-1.494 * 2 *(.166)$ \\
\hline Newspaper reading & $.108(.068)$ & $.165(.103)$ & $-.002(.091)$ & $.102(.070)$ \\
\hline Prefers english & $-.143 *(.068)$ & $-.233+(.125)$ & $-.018(.093)$ & $-.093(.071)$ \\
\hline Homeowner & $-.150 *(.065)$ & $-.186^{*}(.093)$ & $-.118(.079)$ & $-.133^{*}(.066)$ \\
\hline Unemployed & $-.081(.100)$ & $.028(.207)$ & $-.091(.103)$ & $-.080(.100)$ \\
\hline Government Assistance & $.074(.057)$ & $.032(.096)$ & $.086(.072)$ & $.071(.058)$ \\
\hline Catholic & $.355^{* * * *}(.056)$ & $.552^{\text {祡策 }}(.091)$ & 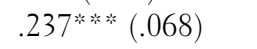 & 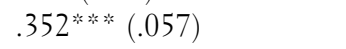 \\
\hline
\end{tabular}




\begin{tabular}{|c|c|c|c|c|}
\hline & $\begin{array}{l}\text { Model 1: all } \\
\text { respondents }\end{array}$ & $\begin{array}{l}\text { Model 2: U.S. } \\
\text { born respondents }\end{array}$ & $\begin{array}{l}\text { Model 3: foreign } \\
\text { born respondents }\end{array}$ & $\begin{array}{l}\text { Model 4: all respondents } \\
\text { (with 3-way interaction) }\end{array}$ \\
\hline Registered to vote & $.314^{* \ldots}(.090)$ & $.101(.117)$ & $.402^{* \ldots+\cdots}(.120)$ & $.280 *(.089)$ \\
\hline Liberal & $.596^{* \ldots *}(.077)$ & 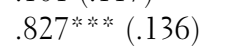 & $.466^{\text {和和 }}(.105)$ & $.604^{*}(.077)$ \\
\hline Union member & $.256^{* *}(.101)$ & $-.016(.117)$ & .587 皮的 $(.115)$ & $.246 *(.101)$ \\
\hline Military & $.123+(.066)$ & $.074(.090)$ & $.097(.095)$ & $.101(.068)$ \\
\hline Cutl & 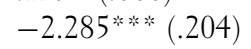 & 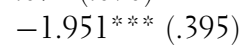 & $-2.571^{\text {事的 }}(.286)$ & -2.294 皮称 $(.227)$ \\
\hline Cut2 & -1.312 皮然 $(.196)$ & $-1.018^{*}(.391)$ & $-1.536^{\text {的的 }}(.261)$ & -1.320 然的 $(.220)$ \\
\hline Cut3 & $-.805^{*}$ 头次 $(.195)$ & $-.670+(.393)$ & $-.913^{\text {为的的 }}(.252)$ & 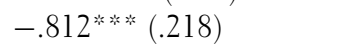 \\
\hline Cut4 & $.672 * * *(.193)$ & $.129(.393)$ & $.899^{*} *(.246)$ & $.667^{* *}(.217)$ \\
\hline Cut 5 & 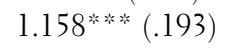 & $.628(.398)$ & 1.389 米祡 $(.247)$ & 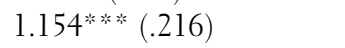 \\
\hline Cut6 & 2.244 米来 $(.197)$ & $1.831^{* * * *}(.396)$ & 2.426 **; $(.246)$ & $2.244 * *(.219)$ \\
\hline \# Observations (\# of clusters) & $7,141(603)$ & $2,214(403)$ & $4,927(504)$ & $7,141(603)$ \\
\hline Pseudo R2 & .0327 & .0341 & .0315 & .0337 \\
\hline
\end{tabular}

LNS National weights used. Robust standard errors in parentheses. $+p<.10,{ }^{*} p<.05, * * *<.01, * * * p<.001$. 


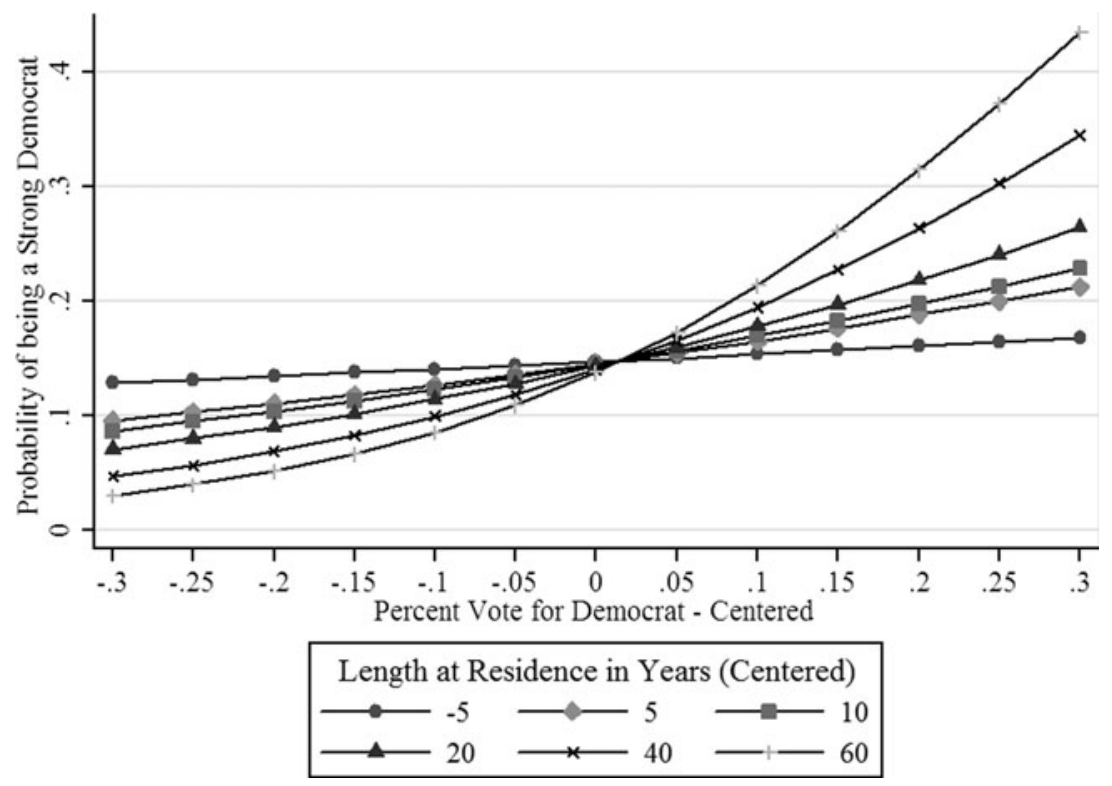

Figure 1. Marginal Effects of Context on Partisan ID Respondents Born Outside the Continental United States.

differences in relationships that might exist across subgroups (Dawson and Ritcher 2006). We attempt to confirm the conditional relationship that was observed in Model 3 by analyzing all respondents and including a three-way interaction term between (1) partisan context; (2) length at residence; and (3) immigrant status (see Model 4). The coefficient for the three-way interaction term is positive and statistically significant and confirms this expectation and suggests the relationship between county context and party identification is conditioned by how long a respondent has lived in the county and whether a respondent is an immigrant. ${ }^{7}$

\section{Regression Discontinuity}

The prediction and the confirmation of a conditional relationship between a county's partisan environment and an individual's partisan attachment, at least for Latino immigrants, help specify one of the mechanisms in which context influences an individual. Living longer in a county exposes one to that environment for a longer period. Further specifications of the mechanisms of how the environment affects an individual 
could be explored. Rutter (2007, 390) notes that "hypothesis-driven" examinations of conditional effects are quite informative for exploring causal relationships. Even so, the fear is researchers will simply "dredge" the data in search for significant interactions. This is problematic because studies have shown conditional relationships are symmetric and therefore, in the end, we cannot be sure our moderating variable is actually acting as a moderator given we only have cross-sectional, nonexperimental data (Berry, Golder, and Milton 2012). The specifying and confirmation of a conditional relationship simply strengthens our casual story; it is not direct evidence of a causal relationship.

There are other designs that can further strengthen claims of causality. One such method is RD. Several scholars have shown that a RD design can produce results from non-experimental data that have high levels of internal validity and are as "credible as those from a randomized experiment" (Lee 2008, 675). We use this technique to confirm that partisan environment influences a foreign-born respondent's self-reported partisan identification. The RD design helps confirm the causality of a relationship by using a cutoff score of a specific measure (sometimes called a rating variable or a forcing variable) to assign observations to a treatment group or a control group.

If the partisan environment influenced the partisan attachments of an individual, we might predict that such an influence would be conditioned on whether the environment reached a certain threshold (a cutoff point). A respondent who lived in a county where $85 \%$ of voters typically vote Democrat does not live in such a different partisan environment as someone who lives in a county where Democrats receive $75 \%$ of the vote. What could matter most is whether Democrats have a majority large enough to place Democrats in local elected positions. Living in a county with $45 \%$ of voters registered as Democrats may actually have a very different partisan environment than a county with $55 \%$. We would expect an observable change in the relationship between an individual's partisan attachment and the percent of the population that is Democratic in a county at a specific value or threshold of partisan context (i.e., $55 \%$ ).

The RD design treats those observations on one side of the threshold of a rating variable as being in the control group and those observations on the other side as belonging to the treatment group. It also assumes that whether an observation is on one side or the other of the threshold is determined randomly. Even if being on one side of the threshold or the other is not determined randomly, the RD design is still considered 
valid as long as subjects cannot easily change which side they are on; or in other words, change where they fall in the rating variable (Lee and Lemieux 2010). For example, although voters can move to a new congressional district to receive better representation (Lee 2008) or a quality congressional candidate could strategically move to a more partisan friendly district (Kousser et al. 2015), these moves appear not to occur in great enough numbers to threaten the assumption that assignment to the control or treatment group functions as if it was randomly determined.

For our study of partisan environment there is some evidence that individuals do incorporate a variety of factors when choosing a place to live, including the political makeup of an area (Tam Cho, Gimpel and Hui 2013). On the other hand, most studies conclude that housing prices, location to employment, proximity to family, and quality of local schools are primary determinants of where a person chooses to live (Clark and Hunter 1992; Greenwood 1975). Furthermore, relocating incurs costs in both time and money and therefore moving from one side of the threshold to the other might not be a feasible action (Lalive 2007).

Early RD studies usually focused on program evaluations and frequently had a rating variable that had a clear demarcation of who is in the treatment group or not (i.e. income eligibility for food stamps). More recent studies are beginning to use some type of geographically bound measure for their forcing variable, such as the party vote share in a congressional district or state (e.g., Caughey and Sekhon 2011; Kousser et al. 2015). We use the geographic context of the partisan vote share in a county to explore the causal connection between partisan environment and an individual's partisan attachment. If we see a "discontinuous" jump or break in the level of the dependent variable (the 7-point partisanship scale) near a threshold point, (55\% of a county voting for a Democratic president), we can infer that this break is caused by crossing this threshold.

In the context of winning or losing an election, a threshold of $50 \%$ share of the vote in the last election is generally seen as a logical predetermined value, at least in a system with two parties. For our analysis we are not interested in marginal or highly competitive districts as some studies are (Lee 2008). Instead, a county should have at least a small margin over the other party to have a noticeable partisan effect on an individual. We borrow the threshold of $55 \%$ frequently cited in the congressional elections literature discussing safe districts (Jacobson 1987) or majority- 
black districts (Grose 2005). Such safe districts (or counties) would then be more likely to have a perceptible partisan environment.

As noted earlier, the RD analysis relies on the assumption of random assignment above and below the predetermined threshold. We test this assumption by examining whether respondents near the threshold (above and below 55\% Democratic vote share) are similar on most attributes. An examination of observations located in counties with Democrat share of the vote $2 \%$ above and below the threshold shows that foreign born respondents are almost identical when it comes to homeownership, percent Catholic, length at current residence, newspaper readership, union membership, language preference, and most importantly, ideology. We did find that foreign born respondents living in counties above the threshold were a bit older, more educated, and less likely to have ever been on government assistance. The similarity between the two groups (above and below the threshold) remains as the bandwidth from the threshold expands to $\pm 5 \%$. Significant differences begin to emerge as the sample is expanded further from the threshold $( \pm 10 \%)$, which would be expected and consistent with prior studies and the assumptions of RD (Lee 2008).

The second step in the RD analysis requires the plotting of the dependent variable against the rating variable to see if a discontinuity or break is visible at the predetermined value. The RD plots in Figure 2 were created by dividing the rating variable into a number of evenly spaced bins and then calculating simple averages of the 7-point partisanship scale within bins and plotting those averages against the rating variable centered at $55 \%$ Democrat share of the vote. The bin averages are plotted to help describe the underlying regression function and superimposed with a line that traces out a second-order global polynomial fit. ${ }^{8}$

Figure 2 displays three graphs of the relationship between the dependent variable (PartyID) and the rating variable (\% share of Democratic vote in the 2000 and 2004 presidential election). RD Plot A contains all respondents in the 2006 LNS dataset, Plot B contains only U.S. born Latinos, and Plot $\mathrm{C}$ includes only Latinos born outside the continental United States. There appears to be a very small discontinuity or break at the designated cut-point or threshold in both Plot A and B, but a much larger break in Plot $\mathrm{C}$, which examines foreign-born respondents.

The third step in our RD analysis was to estimate if the breaks observed in the RD plots are statistically significant. We use a RD design that uses robust bias-corrected confidence intervals to estimate whether the effect of being above or below the threshold is statistically significant (see Calonico, 

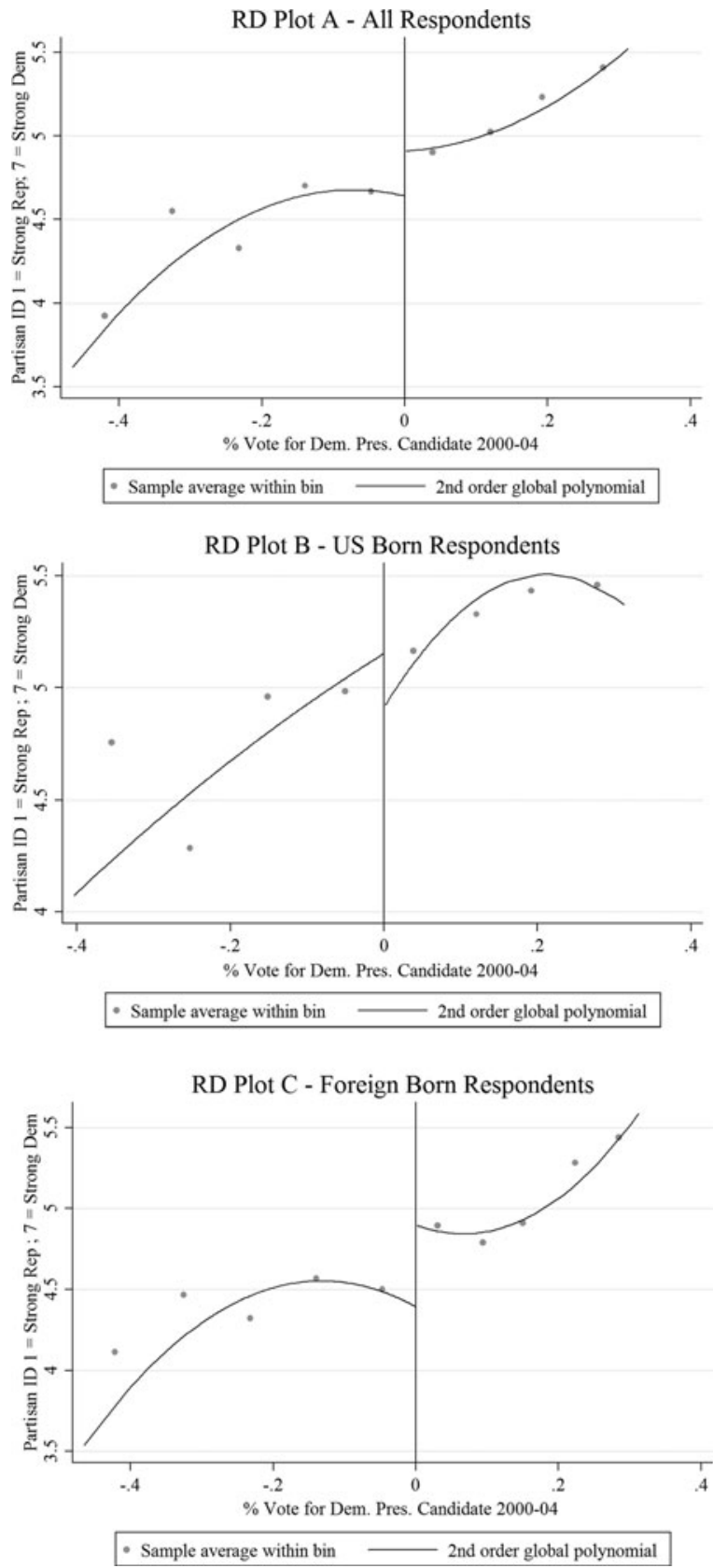

FIguRe 2. Regression Discontinuity Effect of Partisan Environment on PartyID. Points are sample averages within bins set by the IMSE-optimal evenly spaced method. Line traces out a second-order global polynomial fit. 
Table 4. Regression Discontinuity-Partisan ID 7-Point Scale ( 1 = Strong Rep; $7=$ Strong Dem)

\begin{tabular}{lllll}
\hline & $\begin{array}{l}\text { Model 5 } \\
\text { all respondents }\end{array}$ & $\begin{array}{l}\text { Model 6 } \\
\text { U.S. born }\end{array}$ & $\begin{array}{l}\text { Model 7 } \\
\text { foreign born }\end{array}$ & $\begin{array}{l}\text { Model 8 } \\
\text { foreign born (with } \\
\text { control variables) }\end{array}$ \\
\hline RD Estimate $(T=1)$ & .439 & -.943 & $1.078^{* * *}$ & $.699^{* * *}$ \\
Robust Std. Error & .319 & .754 & .357 & 336 \\
Robust p-value & .168 & .403 & .001 & .028 \\
\# Observations & 4,059 & 901 & 2,768 & 2,759 \\
Kernel Type & Uniform & Uniform & Uniform & Uniform \\
Bandwidth Selection & CCT & CCT & CCT & CCT \\
Control Variables & No & No & No & Yes \\
Order Loc. Poly. (p) & 2.000 & 2.000 & 2.000 & 2.000 \\
Order Bias (q) & 2.000 & 2.000 & 2.000 & 2.000 \\
BW Loc. Poly. (h) & .116 & .080 & .117 & .120 \\
BW Bias (b) & .164 & .123 & .176 & .170 \\
\hline
\end{tabular}

$+p<.10, * p<.05, * p<<.01, * * * p<.001$.

$T=1$ for cases above the threshold of $55 \%$ share of vote received by a Democratic presidential candidate in a county (2000-2004 average).

Cattaneo, and Titiunik 2015). The RD design we implemented uses a rectangular kernel (also referred to as a uniform kernel) that focuses the analysis on a range of cases near the threshold. The size of this range or bandwidth is determined using a bandwidth estimator developed by Calonico, Cattaneo, and Titiunik (2015). This bandwidth ranges from $8 \%$ to $12 \%$ of the data above and below the threshold (see Table 4 ). Because the analysis is restricted to this section of data this type of design is sometimes called local linear regression. ${ }^{9}$ Scholars note that such a RD design is a highly valid method of estimating the causal effect of an independent variable on a dependent variable; however, the exclusion of some data points outside the bandwidth reduces the generalizability of the analysis (Kousser et al. 2015). The benefit of using the 2006 LNS is that the study interviewed over 8000 respondents, which facilitates a RD analysis.

Table 4 presents the findings of the RD and the estimate of the treatment effect when a respondent is above the threshold of 55\% Democratic candidate share of the vote $(t=1)$. The treatment effect of being beyond the threshold is not statistically significant for Model 5, which was applied to all Latinos, nor Model 6 applied to U.S. born Latinos. The large discontinuity observed in Plot $\mathrm{C}$ in Figure 2 is 
confirmed to be statistically significant by the RD estimates produced in Model 7 and 8, which are applied to foreign-born respondents only. The coefficient for $t$ (1.078) in Model 7 is in the expected direction ( positive) and statistically significant and can be interpreted to mean that respondents near, but above the partisan threshold are significantly different from respondents near, but below the threshold. This provides evidence of a causal connection between environment and individual partisan attachment. Model 8 presents RD estimates of the treatment effect using the subsample of foreign-born respondent and also controls for the same independent variables controlled for in the models presented in Table 3. ${ }^{10}$ The findings of the RD analysis mirror the findings of the ordered logit models using interaction terms in Table 3. It appears that partisan environment only effects the partisanship attachment of Latinos born outside the continental United States.

\section{CONCLUSION AND DISCUSSION}

The debate over the extent partisanship is influenced by exogenous factors is well cited in the political science literature (Niemi and Weisberg 2001). But this debate is not as well documented in the literature on Latino partisanship. In some cases, the literature finds that Latino partisanship has remained stable over time (de la Garza and Cortina 2007) and partisan attachments in general to be "notoriously sticky" (Dyck, Johnson and Wasson 2012, 44). Yet there are a variety of reasons why one might believe variations in environmental conditions will have an influence on Latino party identification. Because a large proportion of Latinos are new to the political system (Hajnal and Lee 2011) contextual factors may substantially impact partisan attachments. In addition, increased migration out of traditional areas is exposing Latinos to new political conditions and experiences. For example, the states that experienced the largest percentage increase in Hispanic populations from 1990 to 2000 were mostly "red" states: NC, AR, GA, TN, SC, ALA, KY, NE, and MS. These new destinations are clearly different from the traditional locations Latinos occupied in prior periods (Liaw and Frey 2007; Lichter and Johnson 2009).

In this study we explored how contextual factors influence Latino partisanship by examining the 2006 Latino National Survey. We found partisan context was associated with individual-level partisanship only for immigrants and Latinos with both parents born outside the United States. 
For Latinos with one parent (generation 2.5) or both parents (generation 3.0) born in the United States we found no statistically significant association between partisan context and partisanship when controlling for other county and individual level characteristics. If one subscribes to the "traditional" approach to partisanship, the lack of association for later generations of Latinos is not surprising. Under this view partisanship is highly stable, partially because of parental socialization (Campbell et al. 1960). Parental effects are likely much stronger for Latinos born in the United States who also have one or both parents born in the United States. Therefore their partisan ties might be more cemented so that by adulthood the local political environment has much less of an influence. For newer generations, partisan attachments may not be as firmly cemented because their socialization to partisan politics is different (Alvarez and Bedolla 2003; Bowler, Nicholson, and Segura 2006). Furthermore, local partisan environments could have a greater influence on immigrants given that "community-level political activities are open to unauthorized immigrants and legal immigrants not yet eligible for naturalization (DeSipio 2011, 1193).'

The results from this study seem to support these assertions. Through the use of interaction terms we found the relationship between political context (measured by county-level voting data) and partisan affiliation is conditioned on the moderating factor of how long a person lived in that county. However, this conditional effect was only observable for Latinos born outside the United States. We further explored the relationship between partisan context and partisanship using a RD design to determine whether the relationship between context and partisanship is a causal relationship or simply a "phantom" relationship caused by selection effects (Johnson, Shively, and Stein 2002, 219). The results provide evidence the partisan attachments of Latino immigrants are influenced by the partisan environment in which they live. Furthermore, the evidence suggests this relationship is not spurious or simply a sampling artifact.

Prior studies have shown how a single political environment that changes over time can influence Latino partisanship (Bowler, Nicholson, and Segura 2006). Yet few studies have examined how differences in political environments across regions might influence Latino partisanship. Our findings suggest changes across geographic contexts also need to be taken into account to truly understand partisan choice. This may be especially true for Latino immigrants, due to rapid increases in geographic mobility. As Latino immigrants enter the United States from new gateways and Latinos migrate out of traditional metropolitan areas 
and regions, associations, friendships, and communities can change and be redefined. These new and changing "informational environments," may challenge traditional attachments and beliefs, increasing the likelihood of adopting the political orientations of the surrounding political environment.

\section{ACKNOWLEDGMENTS}

The authors would like to thank the anonymous reviewers for their extensive comments. We are also grateful to all the principal investigators of the Latino National Survey for making the data publicly available through the Inter-university Consortium for Political and Social Research (ICSPR). In addition, Matt Barreto provided valuable advice on the measurement of Latino partisanship.

\section{NOTES}

1. Data were obtained from ICPSR dataset 20660 - County Characteristics, 2000-2007.

2. We group Latinos born in Puerto Rico with foreign-born Latinos. Since 1900 all individuals born in Puerto Rico are citizens of the United States. Nevertheless, scholars have noted that the political party system in Puerto Rico developed in a very different political context (Anderson 1965). Thus a Puerto Rican who moves to the continental United States will face a new set of partisan choices. Excluding respondents born in Puerto Rico does not change any of the substantive findings.

3. Democratic presidential candidate vote share variable and the length at residence are centered before creating the product term to make sure there is a meaningful "zero" value (Jaccard 2001).

4. Appendix Table Al contains descriptive statistics for the variables used in the statistical analysis.

5. See Johnson, Shively, and Stein (2002) for a discussion of how the appearance of contextual effects may be due to selection effects of individuals clustered in geographic units.

6. A robust between-cluster variance estimator for cluster-correlated data was used for all models.

7. Dawson and Richter (2006) note the interpretation of three-way interactions is difficult even when plotting the marginal effects. The authors recommend in putting high and low values for the two moderating variables and calculating simple slope differences and significance tests to assist in interpretation. Such a test confirms that the relationship (slope) between partisan context and partisan attachment is significantly larger for immigrants who have lived in a county longer.

8. There are a number of methods to determining the number and size of the bins used in the RD Plot. We use the integrated mean squared-error (IMSE)-optimal choice method described in Calonico, Cattaneo, and Titiunik (2015). The functional form of a second-order global polynomial was selected using the statistical approach describe by Lee and Lemieux (2010).

9. The dependent variable (7-point partisanship scale) is treated as an interval measure. Jacoby (1999) notes the 7-point scale has frequently been justifiably treated as an interval-level measure.

10. If the assignment to the treatment and control group is truly random then there is no need to include other covariates in the RD model. Caughey and Sekhon (2011) note that including or excluding control variables will not bias estimates, however, their inclusion could improve the precision of the estimates. To control for other covariates we created a residualized dependent variable (7-point partyID measure) and then reestimated the treatment effect using RD. The dependent variable is residualized by subtracting from $\mathrm{Y}$ a prediction of $\mathrm{Y}$ based on the control variables (see Winship and Morgan 1999). The inclusion of control variables did make the size of the coefficient smaller, however, it remained statistically significant. 


\section{REFERENCES}

Abrajano, Marisa A., and R. Michael Alvarez. 2010. New Faces, New Voices: The Hispanic Electorate in America. Princeton, NJ: Princeton University Press.

Abramowitz, Alan I., and Kyle L. Saunders. 1998. "Ideological Realignment in the U.S. Electorate." Journal of Politics 60 (3): 634-52.

Achen, Christopher H. 2002. "Parental Socialization and Rational Party Identification." Political Behavior 24 (2): 151-70.

Alvarez, R. Michael, and Lisa Garcia Bedolla. 2003. "The Foundations of Latino Voter Partisanship: Evidence from the 2000 Election.” Journal of Politics 65 (1): 31-49.

Anderson, Robert William. 1965. Party Politics in Puerto Rico. Stanford University Press.

Baik, Ellen R., Jessica Lavariega-Monforti, and Adam J. McGlynn. 2009. "Latino Cabinet Appointments and Young Latino Voters: A Preliminary Look at GOP Efforts to Attract Latino Voters." Social Science Journal 46 (3): 601-8.

Barreto, Matt A., and David L. Leal. 2007. "Latinos, Military Service, and Support for Bush and Kerry in 2004." American Politics Research 35 (2): 224-51.

Bartels, Brandon L., Janet M. Box-Steffensmeier, Corwin D. Smidt, and Renée M. Smith. 2011. "The Dynamic Properties of Individual-Level Party Identification in the United States." Electoral Studies 30 (1): 210-22.

Bartels, Larry M., and Simon Jackman. 2014. "A Generational Model of Political Learning." Electoral Studies 33: 7-18.

Berry, William D., Matt Golder, and Daniel Milton. 2012. "Improving Tests of Theories Positing Interaction." Journal of Politics 74 (3): 653-71.

Bowler, Shaun, Stephen P. Nicholson, and Gary M. Segura. 2006. "Earthquakes and Aftershocks: Race, Direct Democracy, and Partisan Change." American Journal of Political Science 50 (1): 146-59.

Brambor, Thomas, William Roberts Clark, and Matt Golder. 2006. "Understanding Interaction Models: Improving Empirical Analyses." Political analysis 14 (1): 63-82.

Branton, Regina P., and Bradford S. Jones. 2005. "Reexamining Racial Attitudes: The Conditional Relationship between Diversity and Socioeconomic Environment." American Journal of Political Science 49 (2): 359-72.

Brown, Thad A. 1988. Migration and Politics: The Impact of Population Mobility on American Voting Behavior. Chapel Hill: University of North Carolina Press.

Cain, Bruce E., D. Roderick Kiewiet, and Carole J. Uhlaner. 1991. "The Acquisition of Partisanship by Latinos and Asian Americans." American Journal of Political Science 35 (2): 390-422.

Calonico, Sebastian, Matias D. Cattaneo, and Rocío Titiunik. 2015. "Optimal Data-Driven Regression Discontinuity Plots." Journal of the American Statistical Association 110 (512): 1753-69.

Campbell, Andrea Louise, Cara Wong, and Jack Citrin. 2006. “"Racial Threat”, Partisan Climate, and Direct Democracy: Contextual Effects in Three California Initiatives." Political Behavior 28 (2): 129-50.

Campbell, Angus, Philip E. Converse, Warren E. Miller, and Donald E. Stokes. 1960. The American Voter. New York: Wiley.

Caughey, Devin, and Jasjeet S. Sekhon. 2011. "Elections and the Regression Discontinuity Design: Lessons from Close US House Races, 1942-2008.” Political Analysis 19 (4): 385-408.

Clark, David E., and Hunter, William J. 1992. "The Impact of Economic Opportunity, Amenities and Fiscal Factors on Age-Specific Migration Rates.” Joumal of Regional Science 32 (3): 349-65. 
Contreras, A. Reynaldo. 2004. "Epilogue Latinos at the Portal of the 21st Century." Education and Urban Society 36 (2): 223-34.

Cox, David R., and Nanny Wermuth. 2004. "Causality: A Statistical View." International Statistical Review 72 (3): 285-305.

Dawson, Jeremy F., and Andreas W. Richter. 2006. "Probing Three-Way Interactions in Moderated Multiple Regression: Development and Application of a Slope Difference Test." Journal of Applied Psychology 91 (4): 917-26.

de la Garza, Rodolfo O., and Jeronimo Cortina. 2007. "Are Latinos Republicans But Just Don't Know It?: The Latino Vote in the 2000 and 2004 Presidential Elections." American Politics Research 35 (2): 202-23.

de la Garza, Rodolfo O., Louis DeSipio, F. Chris Garcia, John Garcia, Angelo Falcon, and F. Chris Garcia. 1992. Latino Voices: Mexican, Puerto Rican, and Cuban Perspectives on American Politics. Boulder, CO: Westview Press.

DeSipio, Louis. 2011. "Immigrant Incorporation in an Era of Weak Civic Institutions Immigrant Civic and Political Participation in the United States." American Behavioral Scientist 55 (9): 1189-213.

Downs, Anthony. 1957. "An Economic Theory of Political Action in a Democracy." Journal of Political Economy 65 (2): 135-50.

Druckman, James N., and Michael Parkin. 2005. "The Impact of Media Bias: How Editorial Slant Affects Voters.” Journal of Politics 67 (4): 1030-49.

Durand, Roger, and Dennis R. Eckart. 1976. "Contextual Models of Party Identification: A Critical Examination.” Sociological Quarterly 17 (3): 291-302.

Dutwin, David, Mollyann Brodie, Melissa Herrmann, and Rebecca Levin. 2005. "Latinos and Political Party Affiliation." Hispanic Journal of Behavioral Sciences 27 (2): 135-60.

Dyck, Joshua J., Gregg B. Johnson, and Jesse T. Wasson. 2012. "A Blue Tide in the Golden State: Ballot Propositions, Population Change, and Party Identification in California." American Politics Research 40 (3): 450-75.

Fiorina, Morris P. 1981. Retrospective Voting in American National Elections. New Have, CT: Yale University Press.

Flanigan, William H., Nancy H. Zingale, Elizabeth A. Theiss-Morse, and Michael W. Wagner. 2014. Political Behavior of the American Electorate. Washington, D.C.: CQ Press.

Gentzkow, Matthew, and Jesse M. Shapiro. 2010. "What Drives Media Slant? Evidence from US Daily Newspapers.” Econometrica 78 (1): 35-71.

Geron, Kim. 2005. Latino Political Power. Boulder, CO: Lynne Rienner.

Greenwood, Michael J. 1975. "Research on Internal Migration in the United States: A Survey." Journal of Economic Literature 13 (2): 397-433.

Grofman, Bernard, Frank Wayman, and Matthew Barreto. 2009. "Rethinking Partisanship." In Political Parties and Partisan Identification: Social Identity and Individual Attitudes, eds. John Bartle, and Paolo Belluci. New York: Routledge, 60-74.

Grose, Christian R. 2005. "Disentangling Constituency and Legislator Effects in Legislative Representation: Black Legislators or Black Districts?" Social Science Quarterly 86 (2): 427-43.

Hajnal, Zoltan L., and Taeku Lee. 2011. Why Americans Don't Join the Party: Race, Immigration, and the Failure (of Political Parties) to Engage the Electorate. Princeton, NJ: Princeton University Press.

Hayes, Andrew F. 2013. Introduction to Mediation, Moderation, and Conditional Process Analysis: A Regression-Based Approach. New York, NY: Guilford Press.

Jaccard, James. 2001. Interaction Effects in Logistic Regression. Vol. 135, Quantitative Applications in the Social Sciences. Thousand Oaks, CA: Sage. 
Jacobson, Gary C. 1987. “The Marginals Never Vanished: Incumbency and Competition in Elections to the U.S. House of Representatives, 1952-82." American Journal of Political Science 31 (1): 126-41.

Jacoby, William G. 1999. "Levels of Measurement and Political Research: An Optimistic View." American Journal of Political Science 43 (1): 271-301.

Johnson, Martin, W. Phillips Shively, and Robert M. Stein. 2002. "Contextual Data and the Study of Elections and Voting Behavior: Connecting Individuals to Environments." Electoral Studies 21 (2): 219-33.

Johnson, Martin, Robert M. Stein, and Robert Wrinkle. 2003. "Language Choice, Residential Stability, and Voting Among Latino Americans." Social Science Quarterly 84 (2): 412-24.

Kosmin, Barry A., and Ariela Keysar. 1995. "Party Political Preferences of US Hispanics: The Varying Impact of Religion, Social Class and Demographic Factors." Ethnic and Racial Studies 18 (2): 336-47.

Kousser, Thad, Scott Lucas, Seth Masket, and Eric McGhee. 2015. "Kingmakers or Cheerleaders? Party Power and the Causal Effects of Endorsements." Political Research Quarterly 68 (3): 443-56.

Lalive, Rafael. 2007. "Unemployment Benefits, Unemployment Duration, and Post-Unemployment Jobs: A Regression Discontinuity Approach." American Economic Review 97 (2): 108-12.

Lee, David S. 2008. "Randomized Experiments from Non-Random Selection in US House Elections." Joumal of Econometrics 142 (2): 675-97.

Lee, David S., and Thomas Lemieux. 2010. "Regression Discontinuity Designs in Economics." Journal of Economic Literature 48 (2): 281-355.

Leigh, Andrew. 2005. "Economic Voting and Electoral Behavior: How Do Individual, Local, and National Factors Affect the Partisan Choice?" Economics \& Politics 17 (2): 265-96.

Liaw, Kao-Lee, and William H. Frey. 2007. "Multivariate Explanation of the 1985-1990 and 1995-2000 Destination Choices of Newly Arrived Immigrants in the United States: The Beginning of a New Trend?" Population, Space and Place 13 (5): 377-99.

Lichter, Daniel T., and Kenneth M. Johnson. 2009. "Immigrant Gateways and Hispanic Migration to New Destinations." International Migration Review 43 (3): 496-518.

MacDonald, Jason A., and William W. Franko. 2008. "What Moves Partisanship? Migration, State Partisan Environment Ehange, and Party Identification." American Politics Research 36 (6): 880-902.

Marschall, Melissa J., and Dietlind Stolle. 2004. "Race and the City: Neighborhood Context and the Development of Generalized Trust." Political Behavior 26 (2): 125-53.

McBurnett, Michael. 1991. "The Instability of Partisanship Due to Context." Political Geography Quarterly 10 (2): 132-48.

McDaniel, Eric L., and Christopher G. Ellison. 2008. "God's Party? Race, Religion, and Partisanship Over Time.” Political Research Quarterly 61 (2): 180-91.

McGhee, Eric, and Daniel Krimm. 2009. "Party Registration and the Geography of Party Polarization." Polity 41 (3): 345-67.

Medvic, Stephen K. 2013. "On Partisanship." Politics, Groups, and Identities 1 (3): 468-74.

Miller, Warren E. 1991. "Party Identification, Realignment, and Party Voting: Back to the Basics.” American Political Science Review 85 (2): 557-68.

Nicholson, Stephen P., and Gary M. Segura. 2005. "Issue Agendas and the Politics of Latino Partisan Identification." In Diversity in Democracy: Minority Representation in the United States, eds. Gary Segura, and Shaun Bowler. Charlottesville, VA: University of Virginia Press, 51-71. 
Niemi, Richard, and Herbert Weisberg. 2001. "How Much Does Politics Affect Party Identification." In Controversies in Voting Behavior, eds. Richard Niemi, and Herbert Weisberg. Washington, DC: CQ Press, 322-37.

Portes, Alejandro, and Rubén G. Rumbaut. 2001. Legacies: The Story of the Immigrant Second Generation. Berkeley, CA: University of California Press.

Ramakrishnan, S. Karthick. 2004. "Second-Generation Immigrants? The "2.5 Generation" in the United States." Social Science Quarterly 85 (2): 380-99.

Ramakrishnan, S. Karthick. 2005. Democracy in Immigrant America: Changing Demographics and Political Participation. Stanford, CA: Stanford University Press.

Rutter, Michael. 2007. "Proceeding from Observed Correlation to Causal Inference: The Use of Natural Experiments." Perspectives on Psychological Science 2 (4): 377-95.

Smidt, Corwin D. 2014. "Dynamics in Partisanship during American Presidential Campaigns.” Public Opinion Quarterly 78 (S1): 303-29.

Sniderman, Paul M., and Edward H. Stiglitz. 2012. The Reputational Premium: A Theory of Party Identification and Policy Reasoning. Princeton, NJ: Princeton University Press.

Tam Cho, Wendy K., James G. Gimpel, and Iris S. Hui. 2013. "Voter Migration and the Geographic Sorting of the American Electorate." Annals of the Association of American Geographers 103 (4): 856-70.

Taylor, Paul, and Richard Allan Fry. 2007. Hispanics and the 2008 Election: A Swing Vote? Washington, DC: Pew Hispanic Center. http://pewhispanic.org/files/reports/83. pdf (Accessed January 31, 2015).

Therborn, Goran. 2008. "Why and How Place Matters." In The Oxford Handbook of Contextual Political Analysis, eds. Robert Goodin, and Charles Tilly. New York, NY: Oxford University Press, 509-33.

Thurber, Timothy Nels. 2013. Republicans and Race: The GOP's Frayed Relationship with African Americans, 1945-1974. Lexington, KS: University Press of Kansas.

Valentino, Nicholas A., and David O. Sears. 1998. "Event-Driven Political Communication and the Preadult Socialization of Partisanship." Political Behavior 20 (2): 127-54.

Winneg, Kenneth M., Bruce W. Hardy, and Kathleen Hall Jamieson. 2013. “The Impact of 2008 Presidential Campaign Media on Latinos A Study of Nevada and Arizona Latino Voters." American Politics Research 41 (2): 244-60.

Winship, Christopher, and Stephen L. Morgan. 1999. "The Estimation of Causal Effects from Observational Data." Annual Review of Sociology 25: 659-706.

Zuckerman, Alan S., Josip Dasovic, and Jennifer Fitzgerald. 2007. Partisan Families: The Social Logic of Bounded Partisanship in Germany and Britain. New York, NY: Cambridge University Press. 


\section{APPENDIX}

Table Al. Descriptive statistics

\begin{tabular}{|c|c|c|c|c|c|}
\hline Variable & Obs & Mean & SD & Min & Max \\
\hline \multicolumn{6}{|c|}{ Individual-level variables_Latino National Survey, 2006} \\
\hline PartyID & 7,242 & 4.75 & 1.73 & 1 & 7 \\
\hline Age (AGE) & 8,141 & 40.52 & 15.47 & 18 & 97 \\
\hline Education (REDUC) & 8,634 & 3.56 & 1.95 & 0 & 7 \\
\hline Cuban (ETHNIC) & 8,634 & .049 & .215 & 0 & 1 \\
\hline Read Newspaper (READPAPR) & 8,634 & 2.02 & 1.15 & 1 & 4 \\
\hline Read Newspaper (recoded to dummy) & 8,634 & .267 & .443 & 0 & 1 \\
\hline Prefer English (LANGPREF) & 8,634 & .381 & .486 & 0 & 1 \\
\hline Catholic (RELIGION) & 8,634 & .713 & .452 & 0 & 1 \\
\hline Registered to Vote (REGVOTE) & 8,634 & .455 & .498 & 0 & 1 \\
\hline Liberal (IDEOLOGY) & 8,634 & .229 & .420 & 0 & 1 \\
\hline Union Member (UNIONM) & 8,634 & .123 & .328 & 0 & 1 \\
\hline Military (MILITARY) & 8,634 & .314 & .464 & 0 & 1 \\
\hline Length at Residence (LGTHRES) & 8,634 & 10.01 & 16.42 & 0 & 99 \\
\hline Length at Residence (centered) & 8,634 & 0 & 16.42 & -10.01 & 88.99 \\
\hline \multicolumn{6}{|c|}{ Contextual variables: county characteristics, 2000-2007-ICPSR dataset 20660} \\
\hline $\begin{array}{l}\text { \% Democratic Share of Vote: Presidential } \\
\text { Election 2000-04) }\end{array}$ & 8,634 & .523 & .137 & .08 & .87 \\
\hline $\begin{array}{l}\text { \% Democratic Share of Vote: Presidential } \\
\text { Election 2000-04 (Centered) }\end{array}$ & 8,634 & 0 & .137 & -.44 & .35 \\
\hline Median Income/l,000 & 8,634 & 43.26 & 11.03 & 16.50 & 82.93 \\
\hline$\%$ Hispanic in 2005 (logged) & 8,634 & 3.04 & .844 & -.416 & 4.58 \\
\hline Southwest Region & 8,634 & .373 & .484 & 0 & 1 \\
\hline Urban County & 8,634 & .446 & .497 & 0 & 1 \\
\hline
\end{tabular}

